\title{
Intimate Partner Violence among Sample of Married Women Attending Primary Health Care Center in Al-Russafa Sector, 2018 By
}

\section{Dr. Noor Safaa Al-Deen ${ }^{* 1}$; Dr. Lamyaa Ali Hasan ${ }^{* 2}$; Dr. Mushtaq Talib $^{* 3}$}

\author{
${ }^{* 1}$ M.B.Ch.B/FICMS/ Family Medicine Specialist in Ali Al-Garawi PHC for family \\ medecine ${ }^{* 2}$ M.B.Ch.B/FICMS/F.M consultant Family Medicine in Almustanseryia PHC training \\ center for family medicine $/^{* 3}$ Professor of psychiatry ,College of medicine- university of Baghdad
}

\section{Abstract:}

Background: Violence against women is a universal phenomenon that persists in all countries of the world. It's not limited to cultural, geographic, religious, social, economic or national boundaries. therfore aimed of study was Explore the prevalence of IPV against married women attending the primary health care centers (PHCs) of Al Ressafa Sector. Methods: Cross-sectional study with analytic component was carried out on total of 200 women attending in the PHCCs in Al Ressafa Sector during period March- June 2018. A modified version of WHO domestic violence questionnaire was used for the direct interview in this study. All married women attended the PHCCs and meeting the eligibility criteria were informed about the purpose of the study.Results: Out of the total sample (200) the results demonstrated that the overall prevalence of violence was $(80 \%)$; the emotional violence is the most frequent type of domestic violence followed by controlling behavior type (43.5\%), physical violence (36.5\%), economic violence (30\%), and sexual violence (18\%). Conclusions: The majority of women were victims of IPV, and most common type was the emotional violence, followed by controlling behavior. The high rate of IPV need for enacting \& enforcing a national law to combat domestic violence \& screening primary health setting to identify victims of IPV in order to prevent these abuses \& associated unnecessary physical \& mental disability. 
Keywords: Violence, IPV, prevalence, determinants, PHCCs.

\section{Introduction}

Each culture has its sayings and songs about the importance of home, and the comfort and security to be found there. Yet for many women, home is a place of pain and humiliation ${ }^{(1)}$. The family is the first social institution in which personality is shaped and thereby determines the acceptance of values and social norms and their transfer to other social institutions. Despite the important role of this institution in ensuring the safety of individuals, however, it can also be a source of a commonly occurring problem, namely, domestic violence ${ }^{(2)}$.

Violence against women (VAW) is a manifestation of the historically unequal power relations between men and women, which have led to domination over and discrimination against women by men. VAW throughout the life cycle derives essentially from cultural patterns ${ }^{(3)}$.so IPV remains a serious problem in Iraq. The Iraq Family Health Survey (IFHS) 2006/7 found that one in five Iraqi women are subject to physical violence. A 2012 Ministry of Planning study found that at least $36 \%$ of married women reported experiencing some form of psychological abuse from their husbands, $23 \%$ to verbal abuse, $6 \%$ to physical violence, and $9 \%$ to sexual violence ${ }^{(4)}$.IPV is considered a private matter in Iraq, particularly as Iraqi law considers husbands to have a right to discipline their wives, and parents of their children, and women are often under tremendous social and economic pressure to prioritize the family unit over their own protection from violence. Victims often have less bargaining power which skews the outcome of reconciliation processes ${ }^{(5)}$.

IPV is a social problem that, although well-recognized, is still associated with uncertainty and taboos. Many women, in their intimate relationships or immediate social environment, experience psychological and/or physical violence, which becomes a serious health problem for them ${ }^{(6)}$. 


\section{Subjects and methods:}

Cross-sectional study with analytic component was used in this study was conducted in PHCCs of AL-Ressafa sector, Baghdad All 200 married women attended the PHCCs in AL-Ressafa sector, Baghdad and meeting the eligibility criteria were informed about the purpose of the study and those who agreed to participate were given an informed consent and enrolled in the study. Inclusion criteria: Women who are currently married and Women who are previously married ;( separated, divorce, widow). Exclusion criteria: Women who are not married and Women who are mentally ill. the questionnaire was filled through direct interview with the study participants in the selected PHCCs.

The following tools were used:

Statistical Analysis: Each questionnaire assigned with a serial identifying number when the data entered and analysis by the researcher using Statistical Package for Social Sciences (SPSS v.25). Chi-square test applied to test the association between categorical data. so Logistic regression analysis was applied using PPD as the dependent variable and the variables that showed significant association in the binary analysis as the independent variables. The level of significance was set at a $\mathrm{P}$ value of $\leq 0.05$.

\section{Results:}

The distribution of participants by general characteristics is shown in table (1). Age of participants: range from 15 - 74years, with a mean of 39 years and standard deviation (SD) of \pm 13 years. The highest proportion of participants was found in age group 30-44years (42\%). Around (86.5\%) of participants were married. Age at marriage of participants range from 12-38 years with a mean of 22 years and (SD) of \pm 5 year and $(51 \%)$ their age at marriage was between $21-29$ year, $(51.1 \%)$ of participants were married for 1-13 years, (98.5\%) was their first marriage, (56\%) 
having children $\geq 3$, $(52.5 \%)$ were college or higher education, $(5.5 \%)$ were illiterate. About half of participants were housewives. (Table 1)

Table 1: Distribution of participants by general characteristics

\begin{tabular}{|c|c|c|}
\hline Variable & No. $=200$ & $\%$ \\
\hline \multicolumn{3}{|l|}{ Age of wife (years) } \\
\hline $15-29$ & 54 & 27.0 \\
\hline $30-44$ & 84 & 42.0 \\
\hline $45-59$ & 37 & 18.5 \\
\hline $60-74$ & 25 & 12.5 \\
\hline \multicolumn{3}{|l|}{ Marital status } \\
\hline Married & 173 & 86.5 \\
\hline Separated or Divorce & 17 & 8.5 \\
\hline Widow & 10 & 5.0 \\
\hline \multicolumn{3}{|l|}{ Age at marriage (years) } \\
\hline $12-20$ & 86 & 43.0 \\
\hline $21-29$ & 102 & 51.0 \\
\hline $30-38$ & 12 & 6.0 \\
\hline \multicolumn{3}{|l|}{ Marriage duration (years) } \\
\hline $1-13$ & 103 & 51.5 \\
\hline 14- 26 & 52 & 26.0 \\
\hline $27-39$ & 32 & 16.0 \\
\hline $40-53$ & 13 & 6.5 \\
\hline \multicolumn{3}{|l|}{ First marriage } \\
\hline Yes & 197 & 98.5 \\
\hline No & 3 & 1.5 \\
\hline \multicolumn{3}{|l|}{ Number of children } \\
\hline Non & 20 & 10.0 \\
\hline $1-2$ & 68 & 34.0 \\
\hline$\geq 3$ & 112 & 56.0 \\
\hline \multicolumn{3}{|l|}{ Education of women } \\
\hline $\begin{array}{ll}\text { Illiterate } \\
\end{array}$ & 11 & 5.5 \\
\hline Primary & 45 & 22.5 \\
\hline Secondary & 39 & 19.5 \\
\hline College or higher & 105 & 52.5 \\
\hline \multicolumn{3}{|l|}{ Employment status of women } \\
\hline Employed & 80 & 40.0 \\
\hline
\end{tabular}




\begin{tabular}{|c|c|c|}
\hline Housewife & 112 & 56.0 \\
\hline Student & 2 & 1.0 \\
\hline Retired & 6 & 3.0 \\
\hline
\end{tabular}

Table 2 shows the distribution of participants by general characteristics of their husbands. Age of participants' husbands was ranging from 20 to 79 years with a mean of $42( \pm 13 y(\mathrm{SD}))$ years. The highest proportion of participants' husbands was found in age group 35 - 49 years $(35.5 \%)$. The majority was with one wife.

College or higher education was the most common level of education attained by participants' husbands (55\%). About half of the husbands were employed (46\%). The highest proportion was non-alcoholic (88\%), family income was $>1000000$ in (49\%) of participants. Half of the participants' family sizes were with (3-5) members. (Table 2).

Table (2): Distribution of participants by general characteristics of their husbands

\begin{tabular}{|c|c|c|}
\hline \multicolumn{1}{|c|}{ Variable } & No.=200 & $\%$ \\
\hline Partner age (years) & 66 & 33.0 \\
\hline $20-34$ & 71 & 35.5 \\
\hline $35-49$ & 48 & 24.0 \\
\hline $50-64$ & 15 & 7.5 \\
\hline $65-79$ & 184 & 92.0 \\
\hline Number of wives & 11 & 5.5 \\
\hline 2 & 5 & 2.5 \\
\hline$\geq 3$ & 7 & 3.5 \\
\hline Illiterate & 32 & 16.0 \\
\hline Primary & 51 & 25.5 \\
\hline Secondary & 110 & 55.0 \\
\hline College or higher & 92 & 46.0 \\
\hline Employed
\end{tabular}




\begin{tabular}{|c|c|c|}
\hline Unemployed & 11 & 5.5 \\
\hline Free work & 74 & 37.0 \\
\hline Student & 1 & 0.5 \\
\hline Retired & 22 & 11.0 \\
\hline \multicolumn{3}{|l|}{ Alcohol history } \\
\hline Currently alcoholic & 14 & 7.0 \\
\hline Past -alcoholic & 10 & 5.0 \\
\hline Non-alcoholic & 176 & 88.0 \\
\hline \multicolumn{3}{|l|}{ Family income (ID) } \\
\hline$<500,000$ & 42 & 21.0 \\
\hline $500,000-1,000,000$ & 59 & 29.5 \\
\hline$>1,000,000$ & 99 & 49.5 \\
\hline \multicolumn{3}{|l|}{ Family size (No.) } \\
\hline $3-5$ & 103 & 51.5 \\
\hline 6- 9 & 71 & 35.5 \\
\hline $10-13$ & 26 & 13.0 \\
\hline
\end{tabular}

Concerning the controlling type of violence, the results demonstrated that $22.5 \%$ of women reported that their husband restrict their contact with her families, 30.5\% showed that their husbands tried to keep her away from her friends, $18.5 \%$ said that their husband got angry when they spoke to another man, just 3\% of her partners were suspicious and believed they are unfaithful, 13.5\% mentioned that her partner were expect to ask for permission to attained to health care services. As seen in table (3):

Table 3: Frequency of participants for controlling behavior questions

\begin{tabular}{|l|c|c|c|c|}
\hline \multicolumn{1}{|c|}{ Controlling behaviors } & \multicolumn{2}{|c|}{ Yes } & \multicolumn{2}{c|}{ No } \\
\cline { 2 - 6 } & No. & $\%$ & No. & $\%$ \\
\hline $\begin{array}{l}\text { Did your husband tried to restrict contact with your family } \\
\text { of birth? }\end{array}$ & 45 & 22.5 & 155 & 77.5 \\
\hline Did your husband try to keep you from seeing friend? & 61 & 30.5 & 139 & 69.5 \\
\hline Did your husband got angry if you spoke with another man & 37 & 18.5 & 163 & 81.5 \\
\hline $\begin{array}{l}\text { Did your husband where suspicious that you were } \\
\text { unfaithful? }\end{array}$ & 6 & 3.0 & 194 & 97.0 \\
\hline
\end{tabular}


Did your husband expect you to ask for permission before seeing health care for yourself?

27

\begin{tabular}{l|l|l|}
13.5 & 173 & 86.5 \\
& &
\end{tabular}

Regarding the economic violence items, $11.5 \%$ of women reported that their husbands taken her earnings/savings or valuables/other property against their will, $18 \%$ was given up or refused a job for money because her husband did not want her to work, $15.5 \%$ of them was their husbands refuse to give them money for household expenses, even when they had the money for other things. As seen in table (4):

Table 4: Frequency of participants for economic violence questions

\begin{tabular}{|l|c|c|c|c|}
\hline \multicolumn{1}{|c|}{ Economic violence } & \multicolumn{2}{c|}{ Yes } & \multicolumn{2}{c|}{ No } \\
\cline { 2 - 5 } & No. & $\%$ & No. & $\%$ \\
\hline $\begin{array}{l}\text { Has your husband ever taken your earnings/savings or your } \\
\text { valuables/other property from you against your will? }\end{array}$ & 23 & 11.5 & 177 & 88.5 \\
\hline $\begin{array}{l}\text { Have you ever given up or refused a job for money because } \\
\text { your husband did not want you to work? }\end{array}$ & 36 & 18.0 & 164 & 82.0 \\
\hline $\begin{array}{l}\text { Does your husband ever refuse to give you money for } \\
\text { household expenses, even when he has the money for other } \\
\text { things? Or asking for account expenditure? }\end{array}$ & 31 & 15.5 & 169 & 84.5 \\
\hline
\end{tabular}

\section{Discussion:}

In this study forty-two of women fall into (30-44) years category (42\%), a study in Erbil shows the women (25-35years) $(34.5 \%){ }^{(7)}$ And a similar study in Saudi, shows women between (30-40) $(42.5 \%)^{(8)}$. the majority was currently married $(86.5 \%)$ this is similar to study in Erbil $(94.1 \%)^{(7)}$. About half of women married at age between (21-29) years (51\%), for those married at earlier age (12-20) years their percentage was (43\%) as in Iraq the legal age of marriage for both sexes is 18 , however, possible for judge to authorize marriage of girls \& boys as young as 15 , and a study showed that women throughout the Arab region typically married in 
their teens or early $20 \mathrm{~s}^{(9)}$. About half of women were with college qualification $(52.5 \%)$, rate of illiteracy among the sample was about twice the rate of illiteracy in partner $(5.5 \%, 3.5 \%$ respectively) this is similar to UN report in 2009 which shows rate of illiteracy among Iraqi women twice as high as that of men (24\% compared with $11 \%)^{(10)}$. about half of women were housewives $(56 \%)$ this is similar to study in Saudi where housewives percentage was $(57 \%)$, For number of wives the majority was with one wife $(92 \%)$ this is similar to study in Iran $(83 \%)^{(2)}$. About half of partners were with high education (55\%); similar study in Saudi shows percentage of college and high education lower $(39 \%){ }^{(8)}$. Less than half of partner (46\%) were employed, and about one third were free workers (37\%), in similar study in Iran employers percentage was $(80 \%)^{(2)}$. The majority of the husbands were nonalcoholic $(88 \%)$, this similar results to a study shows being married is a way of gaining increased protection against adverse health outcomes, and marriage has a protective effect in reducing the risk of substance abuse ${ }^{(11)}$. For family size this study show higher percentage for those between (3-5) members (51.5\%), a similar study in Iran also shows that family size of (2-4) member represents (54\%) (2).

For emotional violence, more than half of participants showed that their husband insulted her or made her to feel bad about herself $(52.5 \%)$ similar study in Erbil percentage of women insulted by intimate partner was $(40 \%)^{(7)}$, With regards to Physical violence, the most common physical acts women reported that their husband slapped them or thrown something that could hurt them $(30 \%)$, this is similar to study in Erbil (38\%) ${ }^{(7)}$ For sexual violence, the proportion of women physically force into sexual intercourse when they did not want $(12.5 \%)$ was in the range of WHO multi-country study where the proportion of women physically forced into intercourse varied from (4\%) in Serbia and Montenegro to (46\%) in Bangladesh and Ethiopia provinces. 
Emotional violence was the most frequently reported violence type in this study (62\%), same result found in a study in Baghdad that assessed the IPV of women attending Al-Kadhimiya and Al-Kindy hospitals ${ }^{(12)}$, one third of women complain of economic violence in this study (30\%), in similar study in Egypt the economic violence rate was little bit higher $(40 \%){ }^{(13)}$, this is may be due to sociodemographic difference of the population. Economic abuse has previously been conceptualized as a form of emotional violence, it is only recently that researchers have attempted to measure economic abuse as a distinct construct ${ }^{(14)}$, In this study sexual violence prevalence (16\%) was close to studies in Baghdad and Erbil $\left(14.6 \%, 21.1 \%\right.$ respectively ${ }^{(12,7)}$.

In this study the overall violence is significantly associated with marital status $(\mathrm{p}=0.008)$ and it was higher between separated and divorce women $(100 \%)$, this explained as divorce increases after the domestic violence, and the separated women feel less fear when reveal her violence experience ${ }^{(15)}$. so IPV was significant with age at marriage $(\mathrm{p}=0.03)$ where it was higher in those married for (12-20) years (79.1\%), in similar study in Egypt the violence prevalence for those married at age $<20$ were almost the same $(80 \%)^{(13)}$ and low level of education and non-employment consider promoting factor for IPV ${ }^{(1)}$, the number of children also significantly related to overall violence $(\mathrm{p}=0.03)$, where associated with high prevalence in childless (85\%), and those with $\geq 3$ children $(73.2 \%)$, in many cultures, infertile women are at risk of IPV, as well as Low education was associated with increased risk of violence $(\mathrm{p}=0.03)$, where the prevalence was $90.9 \%$ for illiterates and gradually decreases with the increase in the level of education, that may be explained as with lower educational level there is increase in the acceptance of violence and maintains unequal gender norms ${ }^{(16)}$, in other studies, higher educational attainment has been shown to be protective even after controlling for income and age ${ }^{(1)}$. 
The overall violence also related significantly to employment status $(\mathrm{p}=0.04)$, where it is increased in housewives $(77.7 \%)$, in similar study in Saudi the violence to housewives was $(57.9 \%)^{(8)}$, also Number of wives also significantly related to IPV ( $p$ value $=0.02$ ) as it is increased in those married more than one, in similar study in Saudi women with their husband with more than one spouse report higher rate of violence ${ }^{(8)}$, the high percentage of IPV were between those unemployed $(100 \%)$, and free workers $(74.3 \%)$, where economic stress is considered as relationship factor for IPV, when the financial stress increase impacts the couple and commonly cited antecedent to IPV perpetration ${ }^{(17)}$.

Alcohol abuse constantly associated with overall violence ${ }^{(1)}$ where the prevalence for those with currently drinking and past drinking husbands was high (92.9\%, 90\% respectively) which is similar to study in Egypt which show high percentage of IPV among women whom partners are drinkers $(93.7 \%)^{(18)}$, the prevalence of violence increases with the increment of family size (84.6\%) for those with (10-13) member, and increase with the decrement of income were the violence percentage increase for those with monthly income $<500000(83.3 \%)$ that is may be due to increase the burden of responsibility on the husband and put him in financial stress which may increase the IPV, as in Saudi the violence for those with low income was $(59.6 \%)^{(8)}$.

Conclusions: It was concluded that:

1) More than two third of women were victims of intimate partner violence in AlRessafa sector.

2) The most common type of IPV was the emotional violence, followed by controlling behavior, then by physical and economic violence.

3) Proportion of women had combination of more than one type of IPV. 
The most vulnerable groups of women to IPV were those who had: Low in education women; family income and education partner as well as Partner alcohol history ;Unemployed women;Large family size and Other associated factors of IPV were:Marital status (separated or divorce, and widow);Early marriage (10- 20years);Number of children ( $\geq 3$ );Polygamy and Alcohol history of partner

\section{Reference:}

1. WHO. Multi-country study on women's health and domestic violence against women. Geneva: World Health Organization; 2005 [cited 4 July 2018].

2. Shams M, Kianfard L, Parhizkar S, et al. Women's Views about Domestic Violence: A Qualitative Study in Iran. Journal of Interpersonal Violence. 2017; $4: 1-16$

3. Unicef org. Domestic Violence - unicef. 2010 [cited 5 July 2018].

4. Human Rights Watch. DOMESTIC VIOLENCE IN IRAQ. hrw.org. 2017 [cited 26 August 2018].

5. Ronagh J. International Human Rights Law and Domestic Violence. Routledge; 2011[cited 5 July 2018].

6. Flury M, Nyberg E, Riecher-Rössler A. Domestic violence against women: Definitions, epidemiology, risk factors and consequences. Swiss Medical Weekly journal. 2010; 140:45-50

7. Al-Atrushi H, Al-Tawil N, Shabila N. Intimate partner violence against women in the Erbil city of the Kurdistan region, Iraq. BMC Women's Health . 2013 [cited 2 August 2018];13(1):37.

8. Alquaiz A, Almuneef M, Kazi A. Social Determinants of Domestic Violence Among Saudi Married Women in Riyadh, Kingdom of Saudi Arabia. Journal of Interpersonal Violence. 2017;25(1):88-90. 
9. Rashad H, Osman M. MARRIAGE IN THE ARAB WORLD . Assets.prb.org. 2005 [cited 5 August 2018].

10. UN. Iraqi women: Facts \& figures. ReliefWeb. 2009 [cited 5 August 2018].

11.Liew, H. The effects of marital status transitions on alcohol use trajectories. Longitudinal and Life Course Studies. 2012;3(3):332 - 345.

12. Abdul Jabbar MA. The prevalence of violence among a group of married women attending two teaching hospitals in Baghdad. Iraq: Iraqi Council for Medical Specializations Thesis. The New Iraqi Journal of Medicine, Iraqi Council for Medical Specializations; 2007; 3(1): 8-13.

13. Mamdouh H, Ismail H, Kharboush I. Prevalence and risk factors for spousal violence among women attending health care centres in Alexandria, Egypt. Eastern Mediterranean Health Journal. 2012;18(11):1118-1126.

14. Weaver, L. T., Sanders, C. K., Campbell, C. L. et al.(2009) Development and Preliminary Psychometric Evaluation of the Domestic-Related Financial Issues Scale (DV-FI) Journal of Interpersonal Violence. 24(4): 569-585

15.Gallegos J. Domestic Violence and the Duration of Marriage. 1st ed. mysite.syr.edu; 2012 .

16. World Health Organization/London School of Hygiene and Tropical Medicine. Preventing intimate partner and sexual violence against women: taking action and generating evidence. Geneva: World Health Organization, 2010:5-33

17.Garcia-Moreno C. What are the causes of and risk factors for intimate partner violence?. Apps.who.int. 2012 .

18.Lancer D. Forms of Emotional and Verbal Abuse. psychologytoday. 2017 [cited 5 August 2018]. 